\title{
Long-Term Corrosion Studies
}

\author{
Greg Gdowski
}

May 29, 1998

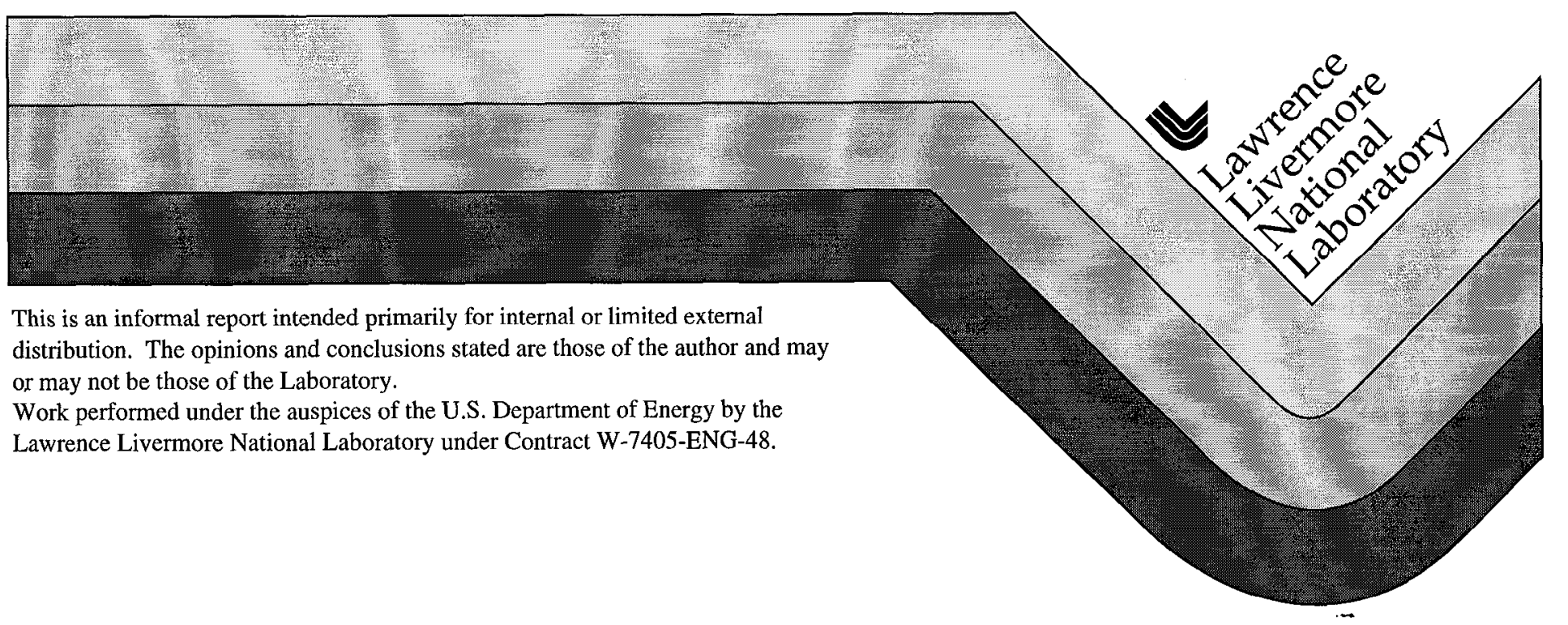




\section{DISCLAIMER}

This document was prepared as an account of work sponsored by an agency of the United States Government. Neither the United States Government nor the University of California nor any of their employees, makes any warranty, express or implied, or assumes any legal liability or responsibility for the accuracy, completeness, or usefulness of any information, apparatus, product, or process disclosed, or represents that its use would not infringe privately owned rights. Reference herein to any specific commercial product, process, or service by trade name, trademark, manufacturer, or otherwise, does not necessarily constitute or imply its endorsement, recommendation, or favoring by the United States Government or the University of California. The views and opinions of authors expressed herein do not necessarily state or reflect those of the United States Government or the University of California, and shall not be used for advertising or product endorsement purposes.

This report has been reproduced directly from the best available copy.

Available to DOE and DOE contractors from the Office of Scientific and Technical Information P.O. Box 62, Oak Ridge, TN 37831

Prices available from (423) 576-8401

Available to the public from the National Technical Information Service

U.S. Department of Commerce 5285 Port Royal Rd., Springficld, VA 22161 
No.: $\quad E-20-50$

Revision: $\quad 4$

Change Notice: $\quad$ E-20-50-4-1

Page: 11 of 20

AUTHOR:

LONG-TERM CORROSION STUDIES

Training Required: Yes $\square$ No

Comments:

Minor change made to Test Materials

\section{REVISION HISTORY}

Rev. No.

CN No.

Effective Date

09/18/89

01/04/95

$11 / 16 / 95$

2

$11 / 16 / 95$

3

$07 / 25 / 96$

4

$04 / 04 / 97$

E-20-50-4-1

$05 / 29 / 98$
Description of Revision/CN

Initial issue

Complete rewrite; addition of Revision History.

Number E-20-50 replaces

E-20-18(b) to agree with SIP-CM-01, Rev. 2. Affects Title Page, Cover Page, page 1, Exhibit $A$ and Exhibit $B$.

Complete rewrite; addition of Appendix A. Affects Title Page, cover page, page $i$, ii, pages 2 through 23 of 23, and Appendix A.

Complete rewrite. Affects Title Page, cover page, pages i, ii, 1 through 16, and Exhibits $A$ and $B$.

Change in Test Materials; repagination. Affects Title Page, and pages 1 and 6 through 13 of 20 .

APPROVALS:

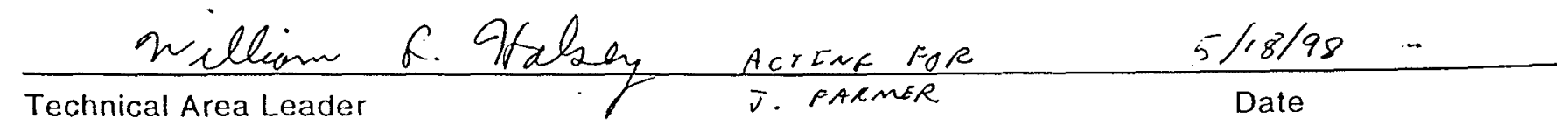




\section{Long-Term Corrosion Studies}

Activity Plan E-20-50

\section{YMP WBS Element 1.2.2.5.1}

LLNL-YMP Metal Barrier Selection and Testing

Lawrence Livermore National Laboratory

Revision 4

Change Notice 1

Effective Date: 05/29/98 


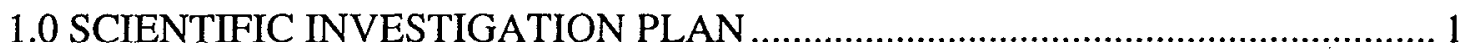

$1.1 \quad$ Activity Identity ................................................................................ 1

1.2 Responsibilities ................................................................................ 1

2.0 SCOPE, PURPOSE, AND OBJECTIVES................................................... 2

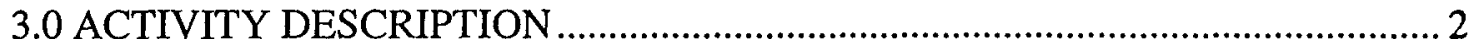

3.1 Technical and Readiness Reviews .................................................... 4

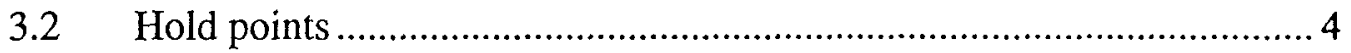

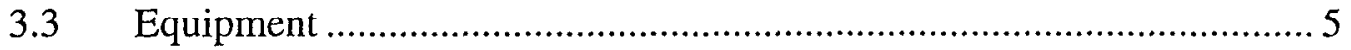

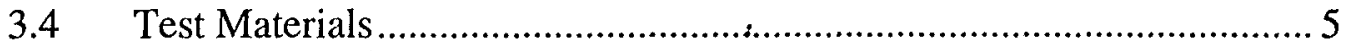

3.5 Test Environments........................................................................... 6

3.6 Special Training/Qualification Requirements ....................................... 7

3.7 Quality Assurance Program.................................................................. 7

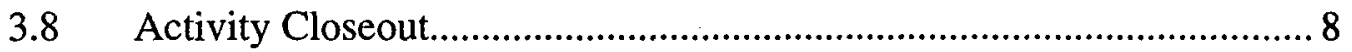

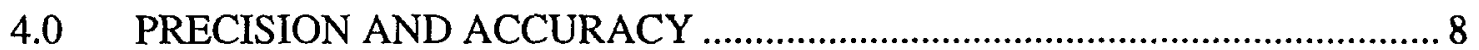

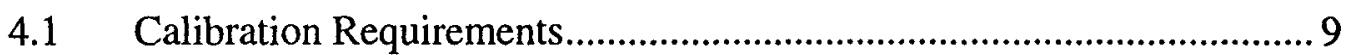

4.2 Conditions which may adversely affect results.................................... 9

4.3 Sources of uncertainty and error to be controlled and measured .............9

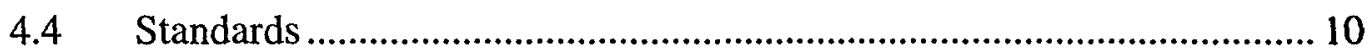

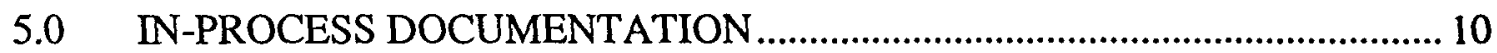

5.1 Data Recording and Data Reduction ..................................................... 11

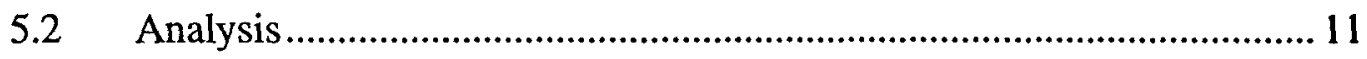

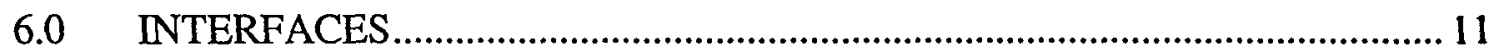

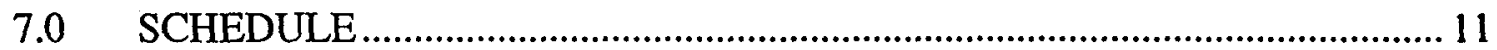

8.0 TECHNICAL IMPLEMENTING PROCEDURES …..................................12

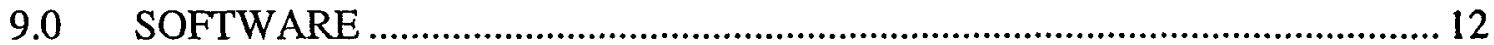

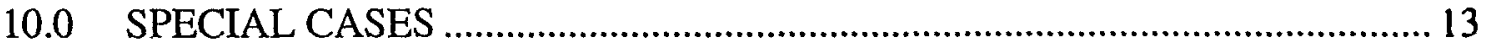

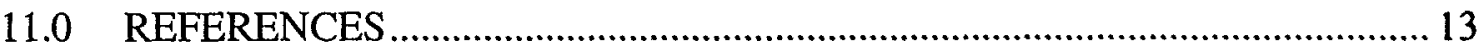

12.0 APPENDIX 


\section{List of Tables}

Page

Table 3.0.1 Test Matrix of Materials and Environments.......................................... 14

Table 3.4.1 Compositions of Candidate Container Materials ..................................... 15 


\subsection{SCIENTIFIC INVESTIGATION PLAN}

This activity plan is written pursuant to Procedure 033-YMP-QP 3.0, "Scientific Investigation Control," of the Lawrence Livermore National Laboratory (LLNL) Yucca Mountain Project Quality Procedures. This plan is written for the Activity entitled "Long-Term Corrosion Studies," which is part of the Scientific Investigation Plan (SIP) "Metal Barrier Selection and Testing" (SIP-CM-01, Rev. 2, WBS \#1.2.2.5.1).

\subsection{Activity Identity}

This activity is entitled "Long-Term Corrosion Studies," and has been assigned the activity number E-20-50. This activity will be performed in accordance with the provisions and requirements of the QARD.

\subsection{Responsibilities}

Key personnel responsible for performing the work in this activity will be:

Technical Area Leader:

Engineered Barrier System Materials

Lead Principal Investigator:

Co-Principal Investigator:

Senior Technologist: 
The scope of this activity is to assess the long-term corrosion properties of metallic materials under consideration for fabricating waste package containers. Three classes of metals are to be assessed: corrosion resistant, intermediate corrosion resistant, and corrosion allowance. Corrosion properties to be evaluated are general, pitting and crevice corrosion, stress-corrosion cracking, and galvanic corrosion. The performance of these materials will be investigated under conditions that are considered relevant to the potential emplacement site. Testing in four aqueous solutions, and vapor phases above them, and at two temperatures are planned for this activity. (The environmental conditions, test metals, and matrix are described in detail in Section 3.0.)

The purpose and objective of this activity is to obtain the kinetic and mechanistic information on degradation of metallic alloys currently being considered for waste package containers. This information will be used to provide assistance to 1) waste package design (metal barrier selection) (E-20-90 to E-20-92), 2) waste package performance assessment activities (SIP-PA-2), 3) model development (E-20-75 to E-2089 ), and 4) repository license application.

\subsection{ACTIVITY DESCRIPTION}

The long-term corrosion properties of metallic alloys under consideration for waste package structural materials will be assessed under a variety of environmental conditions considered relevant for emplacement in unsaturated rock. The test environments include four aqueous solutions, and vapor phases above these solutions. Testing will be performed at two temperatures $\left(60^{\circ}\right.$ and $\left.90^{\circ} \mathrm{C}\right)$ at atmospheric pressure. The aqueous solutions are chosen to bound the range of environments to which these metallic alloys may be exposed. These are as follows: 1) simulated dilute water, which is a low chloride, low sulfate and low bicarbonate water that has ionic concentrations nominally a factor of ten greater than the vadose water expected to be characteristic of the repository horizon; 2) simulated concentrated water, which simulates the concentrating effects of evaporation and boiling of the simulated dilute water; 3 ) low $\mathrm{pH}$ (nominal 2 to 3 ), high ionic content water, to simulate the effect of possible microbial metabolic products; and 4) high pH (nominal 11 to 12) water, to simulate the effect of water contact with cementitious materials used in the construction of the repository. 
Three classes of metallic alloys are to be evaluated: corrosion resistant, intermediate corrosion resistant, and corrosion allowance. The corrosion resistant materials are the high nickel alloys, Alloys $825, \mathrm{G}-3,625, \mathrm{C}-4$, and $\mathrm{C}-22$, and the dilute titanium alloys, Ti-Grades 12 and 16. The intermediate corrosion resistant materials are Monel 400 and 70/30 Cupronickel. The corrosion allowance materials are carbon and low alloy steels: 1018 carbon steel, cast steel, and $2.25 \% \mathrm{Cr}-1 \%$ Mo steel. Welded samples will be tested because of their different susceptibility to corrosion. (Section 3.4 discusses the alloys in more detail.)

A test matrix encompassing various materials and environments is shown in Table 3.0.1. The low-alloy and carbon steels will not be tested in low $\mathrm{pH}$ solutions, since it is known that these materials will degrade rapidly in these solutions. There are a total of 22 solution-temperature-material class combinations that will be investigated. Each of these corresponds to a test vessel in the Integrated Corrosion Facility (ICF) (see Section 3.3 'Equipment').

The types of degradation to be investigated are general corrosion, pitting corrosion, crevice corrosion, stress-corrosion cracking, and galvanic corrosion. Galvanic corrosion will be studied because the current waste package design concepts include the use of multiple metallic barriers. Four types of corrosion specimens will be used to study the various types of corrosion. Standard general corrosion specimens will be used for general and pitting corrosion susceptibility. Crevice assemblies will be used for investigating crevice corrosion. Stress-corrosion cracking will be investigated using Ubend specimens. Galvanic corrosion will be investigated using custom designed galvanically-coupled specimens.

Galvanic specimens will be designed to simulate environmental conditions for the multiple-barrier waste-package design. This design has an inner barrier of a "corrosion resistant" alloy and an outer barrier of a less corrosion resistant alloy (either "corrosion allowance" or "intermediate corrosion resistant").

In order to obtain kinetic and mechanistic data on the degradation phenomena, periodic removal of specimens from the test vessels, and their subsequent analysis are required. Specimen removal from the ICF test vessels has been designed with consideration of minimal disturbance of test environments.

The duration of testing will be a minimum of 5 years. Specimens will be removed at designated intervals which are determined by the Principal Investigators (PI) in 
consultation with the TAL. It will not be a standard practice to return specimens to the test cell after removal. However, if it is deemed appropriate by the PI in consultation with the TAL, some specimens may be reinserted. The decision for such occurrences will be noted in the Scientific Notebook or electronic media.

After exposure, the specimens will be analyzed for kinetic and mechanistic information on the degradation phenomena. This information will be used to provide assistance to 1) waste package design (metal barrier selection) (E-20-90 to E-20-92), 2) waste package performance assessment activities (SIP-PA-2), 3) model development (E20-75 to E-20-89), and 4) repository license application.

\subsection{Technical and Readiness Reviews}

A formal Readiness Review will be held before any quality-affecting experimental work begins. This review will insure that appropriate prerequisites have been satisfied and that programmatic requirement have been identified before starting any quality affecting activity.

\subsection{Hold points}

The operation of the test facility will be monitored on a continuous basis by the Principal Investigator to insure that the work is proceeding according to plan. If significant unanticipated problems arise, the Lead Principal Investigator will inform the Technical Area Leader. A joint decision will be made about the future course of action. The Technical Area Leader will notify the Office of Quality Assurance (OQA) Quality Assurance Representative of any hold points.

The progress of testing will be reported periodically to the Technical Area Leader. If changes in project scope require that experimental work change direction, the Technical Area Leader will communicate this to the Lead Principal Investigator in writing. 


\subsection{Equipment}

This test program will be performed in a custom-designed facility, known as the Integrated Corrosion Facility (ICF), which is described in the system design document (SDD), "Integrated Corrosion Facility," that is included as Appendix A. SDD is a document describing the requirements of the ICF. It may be modified to meet programmatic needs (e.g. budget). As such, it is a living document. ICF is an assembly of multiple corrosion test vessels to pursue the test matrix described in Section 3.0 "Activity Description".

\subsection{Test Materials}

Metallic materials to be tested in this activity are commercially available. For the Metal Barrier Selection and Testing Task purposes, these materials have been classified into three groups based on their corrosion properties: corrosion resistant, intermediate corrosion resistant, and corrosion allowance. The corrosion resistant materials are the high nickel alloys, Alloys C-22, C-4, 625, G-3, and 825, and the dilute titanium alloys, Ti-Grades 12 and 16. The intermediate corrosion resistant materials are Monel 400 and 70/30 Cupronickel. The corrosion allowance materials are carbon and low alloy steels: 1018 carbon steel, cast carbon steel, and $2.25 \% \mathrm{Cr}-1 \%$ Mo steel. Table 3.4.1 shows the common names of the alloys, their Unified Numbering System (UNS) identification numbers, and nominal compositions.

Additional materials may be added to this testing program as warranted by programmatic needs. This will be indicated in the scientific notebook, electronic media, or in changes/revisions to this Activity Plan, depending on the extent of addition.

The materials to be tested in this activity are structural materials that have been commercially used for at least 10 years or more, except for the newly developed TiGrade 16. Ti-Grade 16 is a dilute titanium alloy $(0.05 \mathrm{wt} . \% \mathrm{Pd})$ and is expected to have corrosion resistance similar to that of the higher Pd containing Ti-Grade $7(0.2 \mathrm{wt} . \% \mathrm{Pd})$ under most severe environmental conditions, but at much lower cost [1]. Mechanical properties of Ti-Grade 16 are expected to be intermediate between commercial purity titanium and Ti-Grade 7. 
Since weldments can have corrosion properties different from that of the base metal, specimens of both base metal and welded metal will be used in the testing program. The types of welding processes that will be used on each alloy will be documented.

Test specimens will be purchased from either a YMP approved commercial vendor, or from a commercial vendor with a subsequent check analysis performed by a YMP approved laboratory. Documentation will be obtained from the vendor or the laboratory concerning the relevant information for each metal alloy including, but not limited to such characteristics as the heat number, chemical composition, processing, thermal treatment and resultant mechanical properties. Generally, conformance of these characteristics, particularly chemical composition, is required to ASTM, AWS, or other appropriate metallurgical industrial standards. If the information supplied by the vendor or laboratory indicates that the characteristics of a test specimen or lot of test specimens do not conform to metallurgical industrial standards, then the TAL (or designee) will make a determination of the acceptance or rejection of the particular test specimen or lot of test specimens.

Specimens that are rejected are identified with NCR using QP 15.0.

\subsection{Test Environments}

The test environments include four aqueous solutions and the vapor phases above these solutions. All testing will be performed at atmospheric pressure. The aqueous solutions are chosen to bound the range of environments to which these metallic alloys may be exposed in the potential underground repository. These are as follows: 1) simulated dilute water, which is a low chloride, low sulfate water that is nominally a factor of ten greater than the vadose water that is expected to be characteristic of the repository horizon; 2) simulated concentrated water, which simulates the concentrating effects of evaporation and boiling of the simulated dilute water; 3 ) low pH (nominal 2 to 3) concentrated water, to simulate the effect of possible microbial metabolic products; and 4) high $\mathrm{pH}$ (nominal 11 to 12) water, to simulate the effect of water contact with cementitious materials used in construction of the repository.

Testing in high relative humidity vapor phase above the aqueous solutions will be performed in order to characterize the possible degradation of metals in these 
environments. Previous studies have shown that high relative humidity air can cause accelerated corrosion of metals.

Testing will be performed at approximately $60^{\circ} \mathrm{C}$ and $90^{\circ} \mathrm{C}$ to be representative of the range of temperature where flowing liquid water or condensed water may contact the waste packages.

The compositions of the four aqueous solutions and the procedures to prepare them are described in Technical Implementing Procedures (see section 8.0).

\subsection{Special Training/Qualification Requirements}

Qualifications of the Principal Investigator(s) and technicians are specified by the Technical Area Leader. The Principal Investigator shall have at least a B.S. degree in corrosion engineering, chemistry, chemical engineering, electrochemical engineering, materials science, metallurgical engineering or equivalent. Technical support staff shall have experience in electrochemical or corrosion instrumentation and techniques. Only personnel trained to appropriate quality assurance procedures and any other relevant procedures of the Yucca Mountain Site Characterization Project will be allowed to participate in this activity. Assignment of personnel may change with time. Names of personnel authorized to perform work in this activity will be shown in the appropriate scientific notebook.

\subsection{Quality Assurance Program}

This activity will is to be conducted, subject to the requirements of the QARD, controlled by the selection of applicable quality procedures and appropriate standards. Specific records are generated by implementing quality procedures. These records are "de-facto" evidence of selection and use of the procedures. The plan provides overall guidance for the selection of appropriate Quality controls. The supporting scientific notebooks provide specific evidence of selection and implementation of controls. 


\subsection{Activity Closeout}

As with all other activities in the "Metal Barrier Selection and Testing" task, the major reporting channel is through periodic revision of the Engineered Materials Characterization Report or EMCR, which is Activity E-20-39, in SIP-CM-01, Rev. 2. Supporting documentation such as scientific notebooks and technical report review comments will be retained by the appropriate individual (PI or technical support personnel) until the document package is transferred to the LLNL/YMP Local Records Center at the conclusion of these activities. Many of these records are transferred periodically as record segments so that the final records package of this activity is compiled over a period of time. QA records will be transmitted as described in Procedure 033-YMP-QP 17.0, "Quality Assurance Records."

No additional or special activity close-outs are planned.

\subsection{PRECISION AND ACCURACY}

There are two categories of measurements for this activity. There are measurement devices for control of test parameters, such as temperature, $\mathrm{pH}$, and solution composition. The assessment of these parameters is addressed in the SDD entitled "Integrated Corrosion Facility," which is attached as Appendix A.

The other category of measurements is concerned with the evaluation of the extent of sample degradation (corrosion) after exposure in the ICF. These measurements are aimed at evaluation of weight changes of the specimens, and evaluation of localized attack, such as pitting corrosion, crevice corrosion, and stress corrosion cracking. Analysis will be performed in accordance with standard procedures (e.g. ASTM standards) where applicable. Techniques used will be documented.

Solution $\mathrm{pH}$ is regularly measured in characterizing the test environment. Although a target pH is usually sought, the purpose of the measurement is not so much for control of the $\mathrm{pH}$ as it is to describe the environment. Standard laboratory $\mathrm{pH}$ meters or even indicator papers have sufficient accuracy for this purpose, since only accuracy to the integer value is needed. If a pH meter is used, it will be user-calibrated with use of known buffer solutions just prior to use and following the manufacturer's recommended 
procedure given in the operating manual. Any doubt about the $\mathrm{pH}$ meter or indicator paper is readily resolved by measuring standard $\mathrm{pH}$ buffer solutions.

Test solutions and solution compositions may be verified during the conduct of this activity by laboratory analysis. The purpose of this analysis are not a control of the solution composition but rather an indication of the test environment. Standard laboratory procedures and tests are adequate for these determinations with methods and results documented.

\subsection{Calibration Requirements}

The calibration records will be identified in the scientific notebook and/or electronic media.

\subsection{Conditions which may adversely affect results}

Conditions which may adversely affect the operation of the ICF are listed in the SDD entitled "Integrated Corrosion Facility", that is attached as Appendix A. Adverse conditions such as power failures, that will affect facility operation and data acquisition, and changes in solution compositions are considered. The procedures for returning the facility to normal operations are also discussed in the "Integrated Corrosion Facility" document.

\subsection{Sources of uncertainty and error to be controlled and measured}

Corrosion measurement from a single specimen may be anomalous; therefore, three (3) specimens are required for each test analysis. All results will be reported, together with average values.

ASTM Standards will be followed where appropriate, for evaluating the various corrosion processes. For example, ASTM G 46-94, "Guide for Examination and Evaluation of Pitting Corrosion," will be followed to control and measure such errors and uncertainty. 


\subsection{Standards}

The most current revision of the American Society for Testing and Materials (ASTM) standards to be followed or used for guidance are listed below:

ASTM Designation: G 46-94, "Guide for Examination and Evaluation of Pitting Corrosion"

ASTM Designation: G 78-89, "Guide for Crevice Corrosion Testing of Iron-Base and Nickel-Base Stainless Alloys in Seawater and Other Chloride-Containing Aqueous Environments"

ASTM Designation: G 71-81, "Guide for Conducting and Evaluating Galvanic Corrosion Tests in Electrolytes"

ASTM Designation: G 58-85, "Practice for Stress-Corrosion Test Specimens for Weldments"

ASTM Designation: G 31-72, "Practice for Laboratory Immersion Corrosion Testing of Metals"

ASTM Designation: G 1-90, "Practice for Preparing, Cleaning, and Evaluating Corrosion Test Specimens"

ASTM Designation: G 50-76, "Practice for Conducting Atmospheric Corrosion Tests on Metals"

\subsection{IN-PROCESS DOCUMENTATION}

Documentation to be generated during the conduct of this activity will include scientific notebooks and electronic databases, and may also include data record sheets, raw data, progress reports and the final report. The extent of detail in the documentation will insure that the tests will be repeatable in principle, although the time required to do so in practice would be prohibitive. This is an unavoidable characteristic of longduration tests.

Along with other technical activities in the SIP Metal Barrier Selection and Testing, reporting of the results of this activity will occur on a regular and periodic basis as determined by the schedule of project deliverables. Also, the results will be reported as revisions to the EMCR. As appropriate, topical LLNL reports (UCRL series) will bc prepared on parts of this activity. Interim reports may also be written if deemed appropriate. 
5.1 Data Recording and Data Reduction

Data recording, reduction, and analysis will be done through the use of scientific notebooks, data record sheets, and working electronic spreadsheets/databases.

\subsection{Analysis}

Analyses of the data will be performed where appropriate according to ASTM procedures listed in Section 4.4. Analyses will be recorded in the scientific notebook or electronic media. Analysis procedures not covered in ASTM procedures will be documented in the scientific notebook/electronic media.

\subsection{INTERFACES}

The information obtained in this activity will provide input to the following activities and SIP:

1) Metal Barrier Selection and Testing (E-20-90 to E-20-93)

R. D. McCright, TAL, Engineered Barrier Materials

2) Waste Package Performance Assessment activities (SIP-PA-2)

W. Halsey, TAL, Performance Assessment

3) Model Development (E-20-75 to E-20-89)

R. D. McCright, TAL, Engineered Barrier Materials

After initiation of the experimental work of this activity, the progress reports will be sent to TALs identified with the above SIP and activities. If deemed appropriate, meetings of cognizant PIs to discuss the results from this testing activity will be arranged.

\subsection{SCHEDULE}

Testing will be performed for five years. However, the total duration of this activity will be between 6 and 6.5 years because of the initial ICF construction time and the time required for analysis of the test specimens after exposure. However, depending 
on the future needs and funding levels, some portions of this test may be prolonged indefinitely.

\subsection{TECHNICAL IMPLEMENTING PROCEDURES}

TIPs that are planned for the initialization of this activity will cover the following topics:

1) TIP-CM-01, "Accounting of Test Specimens for the Long-Term Corrosion Testing"

2) TIP-CM-02, "Receiving, Handling, \& Storage of Specimens for Long-Term Corrosion Testing"

3) TIP-CM-03, "Electronic Weight-and-Dimensional-Data Entry in a Computer Database"

4) TIP-CM-04, "User-Calibration of Mettler AT200 Analytical Balance"

5) TIP-CM-05, "User-Calibration of Fowler Ultra-Cal Mark III Digital Caliper"

6) TIP-CM-06, "Formulation and Make-Up of Simulated Dilute Water, Low Ionic Content Aqueous Solution, for Activity E-20-50, "Long-Term Corrosion Studies"

7) TIP-CM-07, "Formulation and Make-Up of Simulated Concentrated Water, a High Ionic Content Aqueous Solution, for Activity E-20-50, "Long-Term Corrosion Studies"

\subsection{SOFTWARE}

Software to be written for this activity will be used for control of the test apparatus. An Individual Software Plan (ISP) has been written for this activity. (See ISP-CM-01) 
The commercial software that will be utilized in operation of the ICF are:

Rocksoft Ladder Logistics for writing and installing the ICF control software,

Wonderware Intouch V 5.0 for Man-Machine Interface routines associated with the ICF control software, and

Microsoft Excel or similar spreadsheet and graphing programs for displaying ICF control and process parameters on a monitor.

Microsoft Access or similar database for cataloging specimen prior to and after testing.

Any software that will be used for analysis of the test data will be identified in the appropriate record.

10.0 SPECIAL CASES

No subcontractors are involved in this activity.

\subsection{REFERENCES}

1) R. W. Schutz, M. Xiao, "Optimized Lean-Pd Titanium Alloys for Aggressive Reducing Acid and Halide Service Environments," 12th International Corrosion Congress, Houston, Texas, 19-24 Sept. 1993, National Association of Corrosion Engineers.

\subsection{APPENDIX}

Appendix A: Initial System Design Document (revised version will be issued upon completion of facility) 
Table 3.0.1. Test matrix of materials and environments.

\begin{tabular}{|cc|cc|cc|cc|}
\hline \multicolumn{2}{|c|}{ J-13 } & \multicolumn{2}{|c|}{$\begin{array}{c}\text { Concentrated } \\
\mathrm{J}-13\end{array}$} & \multicolumn{2}{c|}{$\begin{array}{c}\text { Acidified } \\
\text { concentrated } \\
\mathrm{J}-13\end{array}$} & \multicolumn{2}{c|}{$\begin{array}{c}\text { Alkaline } \\
\text { concentrated } \\
\text { J-13 }\end{array}$} \\
\hline $60^{\circ} \mathrm{C}$ & $90^{\circ} \mathrm{C}$ & $60^{\circ} \mathrm{C}$ & $90^{\circ} \mathrm{C}$ & $60^{\circ} \mathrm{C}$ & $90^{\circ} \mathrm{C}$ & $60^{\circ} \mathrm{C}$ & $90^{\circ} \mathrm{C}$ \\
YES & YES & YES & YES & No & No & YES & YES \\
YES & YES & YES & YES & YES & YES & YES & YES \\
YES & YES & YES & YES & YES & YES & YES & YES \\
& & & & & & & \\
\hline
\end{tabular}

Corrosion

Allowance

Intermediate

Corrosion

Resistant

Corrosion

Resistant 
Table 3.4.1. Compositions of Candidate Container Materials.

\begin{tabular}{|c|c|c|c|}
\hline UNS number & $\begin{array}{l}\text { Common or Commercial } \\
\text { Name }\end{array}$ & ASTM Number & Nominal Composition (weight \%) \\
\hline N08825 & $\begin{array}{l}\text { Alloy } 825 \\
\text { Incoloy } 825\end{array}$ & B 424 (plate) & $\begin{array}{l}\text { Ni } 38.0-46.0 ; \mathrm{Cr} 19.5-23.5 ; \text { Mo } 2.5- \\
\text { 3.5; Fe balance; } \mathrm{Cu} 1.5-3.0 ; \text { Ti } 0.6- \\
\text { 1.2; Mn } 1.0 \max \text {; } 0.05 \max \text {; Si } 0.5 \\
\max ; \mathrm{S} 0.03 \max \text { Al } 0.2 \max \end{array}$ \\
\hline N06030 & $\begin{array}{l}\text { Alloy G-30, } \\
\text { Hastelloy G-30 }\end{array}$ & B 582 (plate) & $\begin{array}{l}\text { Ni balance; } \mathrm{Cr} 28.0-31.5 ; \mathrm{Mo} 4.0-6.0 \\
\mathrm{Fe} 13.0-17.0 ; \mathrm{W} 1.5-4.0 ; \mathrm{Co} 5.0 \max \\
\mathrm{Cu} 1.0-2.4 ; \mathrm{Nb}+\mathrm{Ta} 0.3-1.5 ; \mathrm{Mn} 1.5 \\
\max ; \mathrm{C} 0.03 \max ; \text { Si } 0.8 \max \text { S } 0.02 \\
\max ; \text { P } 0.04 \max \end{array}$ \\
\hline N06625 & $\begin{array}{l}\text { Alloy } 625 \\
\text { Inconel } 625\end{array}$ & B 443 (plate) & $\begin{array}{l}\text { Ni balance; Cr 20.0-23.0; Mo 8.0- } \\
\text { 10.0; Fe 5.00 max; Cb 3.15-4.15; Al } \\
0.40 \text { max; C 0.10 max; Mn 0.50 max; } \\
\text { P 0.015 max; P 0.015 max; S } 0.015 \\
\text { max; Si } 0.50 \text { max; Ti } 0.40 \max \end{array}$ \\
\hline N06455 & $\begin{array}{l}\text { Alloy C-4, } \\
\text { Hastelloy C-4 }\end{array}$ & B 575 (plate) & $\begin{array}{l}\text { Ni balance; Cr 14.0-18.0; Mo } 14.0- \\
17.0: \text { Fe } 3.0 \text { max; Co } 2.0 \max \text {; Mn } 1.0 \\
\max ; \text { C } 0.015 \text { max; Si } 0.8 \max \text { Ti } 0.7 \\
\max ; \text { S } 0.03 \text { max; P } 0.04 \max \end{array}$ \\
\hline N06022 & $\begin{array}{l}\text { Alloy C-22, } \\
\text { Hastelloy C-22 }\end{array}$ & B 575 (plate) & $\begin{array}{l}\text { Ni balance; Cr 20.0-22.0; Mo } 12.5- \\
\text { 14.5; Fe 2.0-6.0; W 2.5-3.5; Co } 2.5 \\
\max \text {; Mn 0.5 max; C 0.015 max; Si } \\
0.8 \max ; \text { V0.35 max; S } 0.02 \max ; \mathrm{P} \\
0.02 \max \end{array}$ \\
\hline R53400 & Ti-Grade 12 & B 265 Grade 12 & $\begin{array}{l}\text { Ni } 0.6-0.9 ; \text { Mo } 0.2-0.4 ; \text { N } 0.03 \max \\
\text { C } 0.08 \text { max; H } 0.015 \text { max; Fe } 0.3 \\
\max \text {; O } 0.25 \text { max; Ti balance }\end{array}$ \\
\hline none to date & Ti-Grade 16 & none to date & $0.05 \mathrm{Pd}$; Ti balance \\
\hline
\end{tabular}


Table 3.4.1. Compositions of Candidate Container Materials (cont'd).

\begin{tabular}{|c|c|c|c|}
\hline UNS number & $\begin{array}{l}\text { Common or Commercial } \\
\text { Name }\end{array}$ & ASTM Number & Nominal Composition (weight \%) \\
\hline N04400 & $\begin{array}{l}\text { Alloy } 400 \\
\text { Monel } 400\end{array}$ & B 127 (plate) & $\begin{array}{l}\text { Ni } 63.0 \text { min; Cu } 28.0-34.0 ; \text { Fe } 2.5 \\
\text { max; Mn } 2.0 \text { max; C } 0.03 \max \text {; Si } 0.5 \\
\max \text { Si } 0.5 \text { max; S } 0.024 \max \end{array}$ \\
\hline C71500 & $\begin{array}{l}70-30 \text { copper-nickel, } \\
\text { CDA } 715\end{array}$ & B 171 (plate) & $\begin{array}{l}\mathrm{Ni} 29.0-33.0 ; \mathrm{Cu} \text { balance; } \mathrm{Mn} 1.0 \\
\max ; \mathrm{Pb} 0.02 \max ; \mathrm{Fe} 0.4-1.0 ; \mathrm{Zn} 0.5 \\
\max ; \mathrm{C} 0.05 \max ; \mathrm{P} 0.02 \max ; \mathrm{S} 0.02 \\
\max \end{array}$ \\
\hline K01800 & 1018 Carbon Steel & A 516 (Grade 55) & $\begin{array}{l}\text { C } 0.18 \text { max; Mn } 0.55-0.98 ; \mathrm{P} 0.035 \\
\text { max; S } 0.04 \max ; \text { Si } 0.13-0.45 ; \mathrm{Fe} \\
\text { remainder }\end{array}$ \\
\hline $\mathrm{J} 02501$ & Centrifugally Cast Steel & A 27 (Grade $70-40$ ) & $\begin{array}{l}\mathrm{C} 0.25 \max ; \mathrm{Mn} 1.2 \max ; \mathrm{P} 0.050 \\
\text { max; } \mathrm{S} 0.060 \text { max; } \mathrm{Si} 0.80 \text { max; Fc } \\
\text { remainder }\end{array}$ \\
\hline K21590 & $2.25 \mathrm{Cr}-1 \mathrm{Mo}$ Alloy Steel & A 387 (Grade 22) & $\begin{array}{l}\mathrm{C} 0.15 \max ; \mathrm{Mn} 0.3-0.6 ; \mathrm{P} 0.035 \\
\max ; \mathrm{S} 0.035 \max ; \mathrm{Si} 0.5 \max ; \mathrm{Cr} \\
2.00-2.50 ; \text { Mo } 0.90-1.10 ; \mathrm{Fe} \\
\text { remainder }\end{array}$ \\
\hline
\end{tabular}




\section{PLANNED TRAINING}

Activity \# Long-Term Corrosion Studies E-20-50

\begin{tabular}{c|c|c|c|}
$\begin{array}{c}\text { Position for } \\
\text { Activity }\end{array}$ & $\begin{array}{c}\text { Person Filling } \\
\text { Position }\end{array}$ & $\begin{array}{c}\text { Training } \\
\text { Required }\end{array}$ & $\begin{array}{c}\text { Date for Completion } \\
\text { of Training }\end{array}$ \\
\hline EXAMPLE: & & & August 1993 \\
\hline Technician & Ron Pletcher & QPS 6.0, 17.0, 13.0 & Before Phase I \\
\cline { 2 - 4 } & & TIPS NF-03, NF-04 & R
\end{tabular}

\begin{tabular}{|l|l|l|l|}
\hline \multirow{4}{*}{$\begin{array}{l}\text { Senior } \\
\text { Technologist }\end{array}$} & \multirow{4}{*}{ J.C. Estill } & QPS 2.1, 2.6, 2.7.3.0, & January 1995 \\
\cline { 3 - 4 } & & $3.3,3.4,4.0,5.0,6.0$, & \\
\hline & $8.0,12.0,13.0,15.0$, & \\
\hline & $16.0,17.0$ & \\
\hline & All TIPs in Activity Plan & \\
\hline & & \\
\hline
\end{tabular}

\begin{tabular}{|l|l|l|l|}
\hline \multirow{4}{*}{$\begin{array}{l}\text { Principal } \\
\text { Investigator }\end{array}$} & G.E. Gdowski & QPs 2.1, 2.6, 2.7, 3.0, & January 1995 \\
\cline { 2 - 4 } $\begin{array}{l}\text { Co-Principal } \\
\text { Investigator }\end{array}$ & F. Wang & $8.0,12.0,13.0,15.0$, & \\
\cline { 3 - 4 } & & $16.0,17.0$ & \\
\cline { 3 - 4 } & & All TIPs in Activity Plan & \\
\hline
\end{tabular}

\begin{tabular}{|l|l|l|l|}
\hline \multirow{4}{*}{$\begin{array}{l}\text { Laboratory } \\
\text { Assistant }\end{array}$} & S.R. Gordon & QP.1, 2.6, 2.7, 3.0, & \\
\cline { 3 - 4 } & S. Doughty & $3.3,3.4,4.0,5.0,6.0$, & \\
\cline { 3 - 4 } & B. Lum & $8.0,12.0,13.0,15.0$, & \\
\cline { 3 - 4 } & & $16.0,17.0$ & \\
\cline { 3 - 4 } & All TIPs in Activity Plan & \\
\hline
\end{tabular}

\begin{tabular}{|c|c|c|c|}
\hline \multirow{6}{*}{$\begin{array}{l}\text { Technical } \\
\text { Area Leader }\end{array}$} & \multirow{6}{*}{ D. McCright } & QPs 2.1, 2.6, 2.7, 3.0, & January 1995 \\
\hline & & $3.3,3.4,4.0,5.0,6.0$ & \\
\hline & & $8.0,12.0,13.0,15.0$ & \\
\hline & & $16.0,17.0$ & \\
\hline & & TIP-CM-03, TIP-CM-04, & \\
\hline & & TIP-CM-05 & $\ldots$ \\
\hline
\end{tabular}


Activity \# Long-Term Corrosion Studies E-20-50

Records to be Completed for this Activity

No Yes

$X \quad$ Publications (If yes, state how many and/or subject/title, if possible, milestone?)

There will be a LLNL UCID report issued at the end of the activity. Interim reports may also be written. The report(s) will describe the extent of the degradation of the metallic alloys in the test environments.

- $\mathrm{X} \quad \begin{aligned} & \text { Technical Implementing Procedures to be written for this activity } \\ & \text { (If yes, state how many and/or subject/title, if possible, milestone?) }\end{aligned}$

Subjects:

Compositions and make-up of aqueous solutions for the ICF

Evaluation of pitting corrosion

Evaluation of stress corrosion cracking

Evaluation of general corrosion

\section{$\mathrm{X} \quad$ Technical Data Input (If yes, state what type, and hold/transfer points for collection, milestone?)}

X Other Records (e.g., Scientific Notebooks). Describe

Scientific Notebooks, samples (corrosion specimens), computer data output 
Appendix A - System Design Description

(10 pages including this cover page) 
Date: 24 April 95

\subsection{General}

This document describes the Integrated Corrosion Facility (ICF) that is to be operated in support of the U.S. Department of Energy's Yucca Mountain Site Characterization Project (YMP). The YMP is evaluating the suitability of Yucca Mountain in Nevada for a high-level nuclear waste repository. In particular Lawrence Livermore National Laboratory (LLNL) is tasked with evaluating potential materials for the waste packages in which the HLW will be emplaced. In the ICF candidate metallic materials will be tested for long-term degradation under repository relevant conditions. The ICF is planned to be in operation for five (5) years.

\subsection{Purpose}

This document defines the process, control, and facility requirements for the Integrated Corrosion Facility system to be built in B-435, Rm 1020. The purpose of the facility is to test metallic specimens for various corrosion modes in aqueous solutions at slightly elevated temperatures. The facility will consist of corrosion vessels in which specimens will be monitored for various corrosion modes including general corrosion, crevice corrosion, localized corrosion (e.g., pitting) and stress corrosion cracking. Specimens will be emplaced in a series of vessels which contain four (4) aqueous solutions at two temperatures $\left(60\right.$ and $\left.90^{\circ} \mathrm{C}\right)$ and atmospheric pressure. The aqueous solutions will be acidic ( $\mathrm{pH} \mathrm{2),} \mathrm{basic} \mathrm{(} \mathrm{pH} \mathrm{10)}$, and neutral. There will be forty-four (44) test vessels in the facility, and extensive control and monitoring systems will be required. The facility system is expected to be in operation for at least five (5) years.

\subsection{Acronyms and Definitions}

ES\&H Environmental, Safety, \& Health

ICF Integrated Corrosion Facility

LLNL Lawrence Livermore National Laboratory

PLC Programmable Logic Controller

SDD System Design Description

YMP Yucca Mountain Site Characterization Project 


\subsection{Test Specimens and Solutions}

Each test vessel will be approximately half-filled with an aqueous solution. (Test vessels will be sealed to minimize vapor losses and ensure constant vapor conditions.) Test specimens will be emplaced in both the aqueous and vapor phases. Specimens will include those that monitor for general corrosion, crevice corrosion, localized corrosion (e.g., pitting), stress corrosion cracking, and galvanic corrosion.

\subsection{Specimen Materials}

The specimens materials are grouped into three general classes based on their corrosion properties. The three classes are "corrosion resistant", "intermediate corrosion resistant", and "corrosion allowance". Table 2.1 lists the specimen materials according to their classes. In general only materials of the same class will be tested in a particular vessel, the exception is for galvanically coupled specimens. 
Table 2.1. Materials to be monitored in the integrated corrosion facility.

UNS Number Common or Commercial Name ASTM Number

\section{Corrosion Resistant}

N08825

Alloy 825 , Incoloy 825

B 424 (plate)

N06985

Alloy G-3

B 424 (plate)

N06022

Alloy C-22, Hastelloy C-22

B 575 (plate)

N06455

Alloy C-4, Hastelloy C-4

B 575 (plate)

R53400

Ti - Gr 12

B 265 Gr 12

none to date

Ti - Gr 16 (Ti-0.05Pd)

none to date

Intermediate Corrosion

Resistant

N04400

C71500
Alloy 400, Monel 400
B 127 (plate)
70-30 Cu-Ni, CDA 715
B 171 (plate)

Corrosion Allowance

$\mathrm{K} 01800$

1018 Carbon Steel

A516 (Gr 55)

$\mathrm{J} 02501$

Centrifugally Cast Steel

A27 (Gr 70 - 40)

K21590

2.25Cr-1Mo Alloy Steel

A387 (Gr 22)

\section{$2.2 \quad$ Specimen Types}

Four types of specimens will be tested in the facility. For each specimen type a minimum of two metallurgical conditions (base metal and welded metal) will be tested. There is the option of including additional specimens that have received a different welding process.

\subsubsection{General weight loss}

Weight loss specimens ( $2 "$ " 1 1" $\times 0.125 ")$ will be monitored for general (weight loss) and localized corrosion (e.g. pitting).

\subsubsection{Crevice corrosion}

Crevice corrosion specimens (2" x 2" x $\left.0.125^{\prime \prime}\right)$ will be monitored for crevice corrosion between an inert crevice former (e.g. Teflon) and a metallic specimen. 


\subsubsection{U-bend}

U-bend specimens will be monitored for stress corrosion cracking (SCC) of the material.

\subsubsection{Galvanic corrosion}

Galvanic corrosion specimens (configuration to be finalized) will consist of plates of dissimilar materials in intimate contact. The configuration of these specimens will be relevant to the concerns of the Yucca Mountain Site Characterization Project (the sponsor of the project). These specimens will be monitored for corrosion caused by the coupling of the dissimilar materials.

\subsection{Test Aqueous solutions}

The following sections described the four test aqueous solutions that will be employed in the facility. The relevant aspects of the test aqueous solution compositions are given in Appendix A. Testing will be in aqueous solutions held at $60^{\circ}$ and $90^{\circ} \mathrm{C}$

\subsubsection{Simulated J-13 water}

The simulated J-13 water has a composition that is similar to that of water drawn from Well J-13 located near Yucca Mountain and is assumed to have a composition that is typical of the low ionic content waters of that area.

\subsubsection{Concentrated simulated J-13 water}

The composition of concentrated J-13 water is that which represents the general composition of the water that is expected to result from the concentrating effects of evaporation and boiling.

\subsubsection{Low $\mathrm{pH}$ water}

In order to at least partly simulate the effect of acid producing microbes (microbially influenced corrosion - MIC) and/or the acidifying effect of introduced materials to the repository, specimens will be tested in an acidic $(\mathrm{pH} 2)$ aqueous solution. The ionic composition will be similar to the concentrated J-13 water. Solutions will be acidified with $\mathrm{HCl}$ (hydrochloric acid).

\subsubsection{High pH water}


Backfill materials may be added to the near field environment or construction materials may be employed that change the $\mathrm{pH}$ value of local water. Testing will be performed in water with $\mathrm{pH} 10$. The ionic composition will be similar to the concentrated $\mathrm{J}-13$ water. Solutions will be alkalized with $\mathrm{NaOH}$ (sodium hydroxide).

\subsection{Test Matrix}

In general, each test vessel will contain only specimens of the same class of materials, the exception is the galvanic specimens which are couples of dissimilar materials. Each class of materials, the corrosion resistant, intermediate corrosion resistant, and corrosion allowance, will be tested in 8 environments ( 4 solutions and 2 temperatures), except that the corrosion allowance materials will not, be tested in the acidic solutions (pH 2). The test matrix of materials and aqueous solution is shown in Table 2.2. This test matrix calls for 22 test vessels based on materials and solutions. This number is doubled because separate vessels are required for the galvanic specimens. The total number of vessels is 44 , however the size may vary based on the number of specimens required to be emplaced in the vessel.

Table 2.2. Test matrix of materials and environments.

$\begin{array}{cccccc}\mathrm{J}-13 & \begin{array}{c}\text { Concentrated } \\ \mathrm{J}-13\end{array} & \begin{array}{c}\text { Acidified } \\ \text { concentrated } \\ \mathrm{J}-13\end{array} & \begin{array}{c}\text { Alkaline } \\ \text { concentrated } \\ \mathrm{J}-13\end{array} \\ 60^{\circ} \mathrm{C} \quad 90^{\circ} \mathrm{C} \quad 60^{\circ} \mathrm{C} \quad 90^{\circ} \mathrm{C} & 60^{\circ} \mathrm{C} \quad 90^{\circ} \mathrm{C} & 60^{\circ} \mathrm{C} \quad 90^{\circ} \mathrm{C}\end{array}$

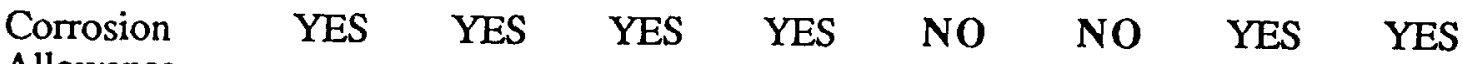

Allowance

$\begin{aligned} & \text { Intermediate } \\ & \text { Corrosion }\end{aligned}$
Res

Resistant

Corrosion

Resistant

YES YES YES YES YES YES YES YES




\subsection{Test Vessel Requirements, and Process Monitoring and Control Requirements}

In each of the 44 test vessels, specimens will be in the liquid phase and in the vapor. phase above the aqueous solutions. For corrosion monitoring purposes specimens will be removed periodically with minimal disturbance of the conditions in the test vessels. In addition to the specimens each test vessel will contain several process monitoring and control devices. The process parameters to be controlled and/or monitored are:

1) temperature,

2) aqueous solution composition,

3) $\mathrm{pH}$,

4) oxygen concentration, and

5) water level.

Table 3.1 lists the various monitoring and data acquisition devices and their functions. The following sections outline the requirements for test vessels, and the process monitoring and control devices.

\subsection{Test vessels}

The requirements on each test vessel are:

- at least five (5) specimens racks must be independently removable.

- materials of construction must be compatible with the aqueous solutions (i.e., construction materials will not dissolve, corrode, release deleterious ions into the solutions).

- each vessel will be sealed in order to minimize water vapor losses.

- all monitoring and control devices are to be fed through the vessel lid.

- a low flow purified air feed line will supply a constant flow of air to the vapor phase

- a condenser will remove water vapor from the air exiting the vessel. This may require a LCW hook up. A check valve will be attached to the exit of the condenser.

- solutions will be heated by resistance heaters that will be emplaced in the liquid phase

- the thermocouples in the liquid phase will be placed away from the heater and must be replaceable.

- the vessel will be insulated.

- means will be taken to eliminate dripping of condensed water (from the condenser and the vessel lid) from dripping on the specimens in the vapor phase.

- there will be a port to withdraw the aqueous solution from the vessel from at least two (2) regions in the vessels. 
- the liquid phase will be stirred.

- vessels will have a means for adding additional solution.

- vessel will have an automatic purified water fill.

\subsection{Temperature}

The temperature of the liquid phase and the vapor phase will be monitored with Type "K" thermocouples. An additional thermocouple in the liquid phase will be used for overtemperature control.

\subsection{Aqueous solution composition}

The aqueous solution composition will be monitored periodically by withdrawing liquid from the vessel. If the solution composition varies beyond set limits, to be determined, measures will be taken to return the composition to within its set limits.

\section{$3.4 \mathrm{pH}$}

The pH of the aqueous solutions will be kept within set limits. This will be accomplished by monitoring the solution $\mathrm{pH}$ and taking appropriate means to keep the solution within the acceptable limits. Monitoring of the solution pH can be taken by sensor immersion in the solution, or withdraw of solution and analysis of that solution.

\subsection{Oxygen concentration}

The oxygen concentration of a solution may be obtained by withdrawing some of the solution and analyzing it for oxygen content.

\subsection{Water level}

The water level in the test vessels will be maintained at a specified level in order to keep the specified specimens submerged in liquid. A level sensor will be used to monitor the water level. When necessary purified water will be added automatically to the vessel to maintain the correct water level. Since the test vessels will have constant air purges water losses in the vapor phases will have to be minimized. Each test vessel will be equipped with a condensation baffle. 


\subsection{Building and room requirements}

The building and room must meet or be modified to meet the following requirements:

- adequate space for all the test vessels

- adequate power to heat and maintain the aqueous solutions in the test vessels

- meet all Environmental, Health, and Safety (ES\&H) requirements

- wastewater retention system

- adequate ventilation

- eyewash and shower station

- other

- low conductivity water (LCW)

- additional water supply (distilled and deionized wáter)

- a work area

\subsection{Data Acquisition / Display and Process Monitoring System}

The data acquisition / display and process monitoring system shall consist of a programmable logic controller (PLC) and a computer. The PLC will monitor and control process parameters. The computer will accept and display process parameters and alert personnel of process parameters that are out-of-range.

\subsection{Programmable Logic Controller}

The PLC will monitor and control the following:

- aqueous levels in the vessels

- the temperatures of the aqueous solutions

\subsection{Computer Requirements}

Data acquisition / display and process monitoring will be performed on a computer. The computer will store and display process parameters. Process parameters can be entered manually (from the keyboard) and directly from process sensors (see below). The monitor will display out of range parameters. The computer will still function if data from a vessel is no longer available. Data will be stored so as to minimize lost data due to unexpected circumstances. 


\subsection{Displayed Data}

The following items shall be capable of being displayed on the computer monitor for each test vessel:

- temperature (sensor)

- $\mathrm{pH}$ (manual)

- solution composition (manual)

- oxygen concentration (manual)

\subsection{Process Safety Requirements}

For safety concerns, some means will be instituted to contol:

- Over-pressurization of vessels (pressure relief valve)

- Over-temperature

- Water over flow 